\title{
Inter- and intra-shoot distributions of the ramie moth caterpillar, Arcte coerulea (Lepidoptera: Noctuidae), in ramie shrubs
}

\author{
Jun-Ya IDE* \\ Department of Environmental Science, Graduate School of Science and Technology, Kumamoto University; Kumamoto 860-8555, \\ Japan
}

(Received 23 May 2005; Accepted 19 September 2005)

\begin{abstract}
I investigated inter- and intra-shoot distributions of the caterpillars of the ramie moth Arcte coerulea in shrubs of the host plant China ramie, Boehmeria nipononivea. The caterpillars were distributed on long shoots in the canopy of ramie, and caterpillar performance was better when they fed on leaves of the canopy shoots rather than those of the understory shoots. This was probably because the caterpillars could overcome the host plant defense to obtain nutrition from the sunlit shoots, which often contain higher concentrations of chemical defenses. Within a shoot, caterpillars were found on leaves that had just completed expansion. This leaf preference was probably affected by the change in food quality with leaf age. Caterpillars were never observed on buds, and their performances were poor when they fed on buds. This suggests that the chemical defense is heavily concentrated in buds. Outbreaks of $A$. coerulea frequently occur and cause defoliation of host plant shrubs; this may have resulted in accelerated evolution of host plant defense for rapid regrowth of the foliage, which contributes to the plant's tolerance of these moth caterpillars.
\end{abstract}

Key words: Leaf position; outbreak; plant defense; relative growth rate; specialist herbivore

\section{INTRODUCTION}

Many herbivorous insects show a feeding preference within a host plant. Identifying the determinant of herbivore feeding preferences for plants or plant parts is a main focus of plant-animal interaction studies (White, 1984; Coley et al., 1985; Price, 1991; Aide, 1993). Plant quality as food for herbivores differs among plant individuals; these differences are often caused by differences in chemical compounds, including those for defense, that depend on water, light, and other resource conditions (White, 1984; Koricheva et al., 1998). In addition, within-plant variation in quality exists among organs or tissues because of heterogeneous resource and defense allocation (Orians and Jones, 2001). Herbivores have higher fitness when they selectively feed on high-quality plants or plant parts. However, high-quality plants or plant parts are not always available, and herbivorous species may lack the ability to overcome plant defenses; for example, the ability to detoxify certain chemicals (van der Meijden, 1996; de Boer, 1999). The ability of a herbivore to overcome plant defenses may depend on its degree of specialization on the host plant. In general, specialist herbivores whose host range is narrow are better adapted to their host plants than are generalists, and so they are more likely to be able to overcome defenses and obtain high-quality plants or plants parts (Cates, 1980; Wittstock and Gershenzon, 2002). The feeding preference of herbivores reflects this plant-herbivore interaction. Evaluation of both plant resource and defense allocation and the ability of herbivores to cope with plant defenses are necessary to understand the mechanisms responsible for the heterogeneous distribution of insect herbivores among their host plants.

The resource and defense contents of plant parts usually vary with the age of the parts. Many plants invest nutrients in young parts that contribute more to plant fitness (Harper, 1989). This makes young plant parts valuable for herbivores, and many plants protect these parts from herbivory with tri-

\footnotetext{
* Present address: Laboratory of Insect Ecology, Graduate School of Agriculture, Kyoto University, Kyoto 606-8502, Japan.

E-mail: idejy@kais.kyoto-u.ac.jp

DOI: 10.1303/aez.2006.49
} 
chomes, chemicals, and other defenses (Bowers and Stamp, 1993; van Dam et al., 1996; Van Alstyne et al., 1999; Cardoza et al., 2000; Fordyce and Agrawal, 2001). As an adaptation to age-related resource and defense gradients within a single plant, herbivores often exhibit feeding preferences based on the age of plant parts (Hartnett and Bazzaz, 1984; van der Meijden, 1996; de Boer, 1999). In addition, feeding preferences are likely to differ between specialist and generalist herbivores. Similarly, resource and defense gradients may exist among plants under a variety of environmental conditions. For example, sunlit plants often take up more water and nutrients from roots than do shaded plants, and also contain higher concentrations of carbon-based secondary compounds, such as phenolics and terpenoids, that are believed to function as chemical defense against herbivory (Koricheva et al., 1998; Orians and Jones, 2001).

The caterpillar of the ramie moth, Arcte coerulea Guenée (Lepidoptera: Noctuidae), is an Urticaceae specialist (Esaki et al., 1971). The main host plant in Japan is China ramie, Boehmeria nipononivea Koidz. Because A. coerulea often outbreaks on and defoliates ramie, it was considered a serious pest when ramie was cultivated as a fiber crop on a large scale in Japan (Ohtaishi, 1977). At present, $B$. nipononivea is mainly found in open areas such as along river-banks and on vacant land in suburban areas. Shoots of B. nipononivea with alternate leaves grow vertically from belowground or near-ground stems, and dense monospecific stands are often formed. Therefore, differences in light availability and plant growth between the canopy and understory are probably very significant within a stand of shrubs. Arcte coerulea caterpillars can wander among crowded ramie shoots; thus, their distribution will reflect their feeding site preferences.

In this study, I analyzed the leaf-feeding patterns of $A$. coerulea caterpillars to determine how a specialist herbivore copes with the allocation of resources and defenses within a host plant. First, inter- and intra-plant caterpillar distributions in ramie shrubs were investigated. Because $A$. coerulea is a specialist herbivore, the caterpillars are predicted to be distributed on young leaves of shoots in the canopy. Second, caterpillar performance was compared among leaf positions within a shoot. I then estimated the resource and defense al- location of ramie, and discussed the factors affecting the feeding preference of $A$. coerulea caterpillars.

\section{MATERIALS AND METHODS}

Plants and insects. This study was conducted at Tatsuda-yama hill, in Kumamoto, southern Japan $\left(130^{\circ} 44^{\prime} \mathrm{E}, 32^{\circ} 49^{\prime} \mathrm{N}, 40 \mathrm{~m}\right.$ above sea level). Many dense stands of $B$. nipononivea are found in this area. These ramie stands are mown periodically, so that the plants are usually $<1.5 \mathrm{~m}$ tall, regardless of the season.

Arcte coerulea is multivoltine, and the caterpillars appear from spring to autumn. Outbreaks of the caterpillars often occur in August and September in Kumamoto (J.-Y. Ide, personal observation). Larval body color changes depending on the population density. Black bands on the thorax and abdomen of the third to sixth instars are narrow under solitary conditions (solitary phase); the bands widen conspicuously under crowded conditions (gregarious phase) (Ohtaishi, 1977; Ikemoto, 1984). This study was conducted on caterpillars in the gregarious phase.

Inter- and intra-shoot caterpillar distribution. The inter- and intra-shoot distribution of $A$. coerulea caterpillars was investigated in two ramie shrub stands (stands A and B) on 3 and 4 September 2003. The distance between the stands was approximately $4 \mathrm{~m}$, and shoot densities were similar (A, 94 shoots $/ \mathrm{m}^{2} ; \mathrm{B}, 99$ shoots $/ \mathrm{m}^{2}$ ). In these two stands, no plants possessed floral buds. Many $A$. coerulea caterpillars were found on the shoots, and most were of the gregarious phase. The caterpillars had not yet defoliated the ramie. A $1 \times 1 \mathrm{~m}$ quadrat was established in each stand. Every shoot in the quadrat was examined, and three characteristics were recorded: shoot length, number of leaves on the shoot, and whether the shoot constituted the canopy (canopy shoot) or was covered by surrounding shoots (understory shoots). When third instar or older caterpillars were found, the instar and the leaf position occupied were also recorded. The first leaf from the shoot apex that was $>30 \mathrm{~mm}$ in length was designated as leaf position 1, i.e., the index leaf. All distal leaves from the index leaf that were $\leq 30 \mathrm{~mm}$ long, were considered to be in leaf position 0 . All other leaves were numbered relative to the position of the index leaf. 
To determine whether caterpillar shoot preference was affected by shoot size, I analyzed the relationship between shoot length and the number of caterpillars on each canopy shoot. Large shoots with many leaves tended to have larger leaves (unpublished data). To exclude the effect of resource abundance (i.e., leaf number and area), I also analyzed the relationship between shoot length and the number of caterpillars on each canopy shoot divided by the leaf number, and by the square of the length of the largest leaf. Because the length of the largest leaf was correlated with leaf number $\left(R^{2}=0.648, n=18, p<0.0001\right)$, the length of the largest leaf on each shoot was not measured, but was estimated using the following equation:

largest leaf length $=3.69 \times$ shoot leaf number $+48.24(\mathrm{~mm})$.

Effect of light availability on host plant growth. To determine the effects of light availability on the plants, the growth of ramie shoots was compared between canopy shoots and understory shoots in August 2003. Five canopy shoots and five understory shoots were chosen on a ramie shrub with no floral buds at Kumamoto University, and shoot length and the number of leaves on each shoot were recorded. A numbered tag was placed on the stem of each shoot. After $13 \mathrm{~d}$, the marked shoots were re-measured. The initial number of leaves per shoot did not differ between treatments (mean \pm SD: canopy, 11.4 \pm 2.4 ; understory, $11.0 \pm$ 2.1; Mann-Whitney $U$-test: $z=-0.213, p=0.832$ ).

Insect performance. To assess the inter- and intra-shoot variation in leaf quality, a bioassay in which caterpillars were reared on leaves of different ages and light availability was conducted in September 2003. Leaves were divided into five categories as follows: canopy leaf buds (leaf positions 0 and 1), mature canopy leaves (i.e., those at the shaded-unshaded boundary in Fig. 2 that had recently completed expansion; unpublished data), old canopy leaves (i.e., those three leaves from the lowest position on each shoot), understory leaf buds, and mature understory leaves. Individual third instar caterpillars, $(n=18$ for each treatment $)$, collected from a ramie stand at Kumamoto University, were weighed and placed in Petri dishes with a wet paper towel and leaves of each category collected from ramie stands with no floral buds. The leaves were replaced twice daily with freshly collected leaves. Caterpillars were reared under natu- ral day length and temperature conditions for $5 \mathrm{~d}$, and then they were weighed again. Larval performance was assessed by the relative growth rate, calculated as:

relative growth rate

$=($ final weight - initial weight $) /$ initial weight.

Relative growth rates were compared among leaf categories using analysis of variance (ANOVA) with post-hoc Tukey HSD multiple comparisons.

\section{RESULTS}

\section{Inter- and intra-shoot caterpillar distribution}

Sixty nine and 56 caterpillars of A. coerulea (third to fifth instar) were observed in stands A and $\mathrm{B}$, respectively. Instars did not differ in the sites used. Most caterpillars were found on large ramie shoots that formed the shrub canopies (Fig. 1). The proportion of shoots used by caterpillars was significantly higher for the canopy shoots than for the understory shoots (Fisher's exact probability test: stand $\mathrm{A}, p<0.001$; stand $\mathrm{B}, p<0.001$ ). The number of the caterpillars on a canopy shoot was positively correlated with shoot length (stand $\mathrm{A}, R^{2}=0.097$, $n=46, p=0.035$; stand $\mathrm{B}, R^{2}=0.215, n=42, p=$ $0.002)$. When the effects of leaf number and area were excluded, weak positive correlations remained (stand $\mathrm{A}, R^{2}=0.065, n=46, p=0.089$; stand $\mathrm{B}$, $\left.R^{2}=0.121, n=42, p=0.024\right)$. This indicates that caterpillars had a slight preference for longer shoots.

Within a shoot, caterpillars were distributed on the middle leaf positions and rarely used buds and old leaves (Fig. 2). Caterpillars tended to be found at lower leaf positions when they were on long, well-developed shoots with many leaves [logistic regression: stand $\mathrm{A}$, likelihood ratio (LR) $\chi^{2}=7.97$, $\mathrm{df}=1, p=0.005 ;$ stand $\mathrm{B}, \mathrm{LR} \chi^{2}=8.12, \mathrm{df}=1$, $p=0.004]$.

\section{Effect of light availability on host plant growth}

Canopy shoots of $B$. nipononivea had higher growth rates than did understory shoots, as assessed by leaf production and shoot elongation. Canopy shoots produced more leaves (mean \pm SE: canopy, $0.34 \pm 0.05$ leaves $/ \mathrm{d}$; understory, $0.08 \pm$ 0.02 leaves/d; Mann-Whitney $U$-test: $z=-2.55$, $p=0.01$ ) and grew longer (mean $\pm \mathrm{SE}$ : canopy, $1.14 \pm 0.14 \mathrm{~cm} / \mathrm{d}$; understory, $0.06 \pm 0.04 \mathrm{~cm} / \mathrm{d}$; Mann-Whitney $U$-test: $z=-2.51, p=0.01$ ). 


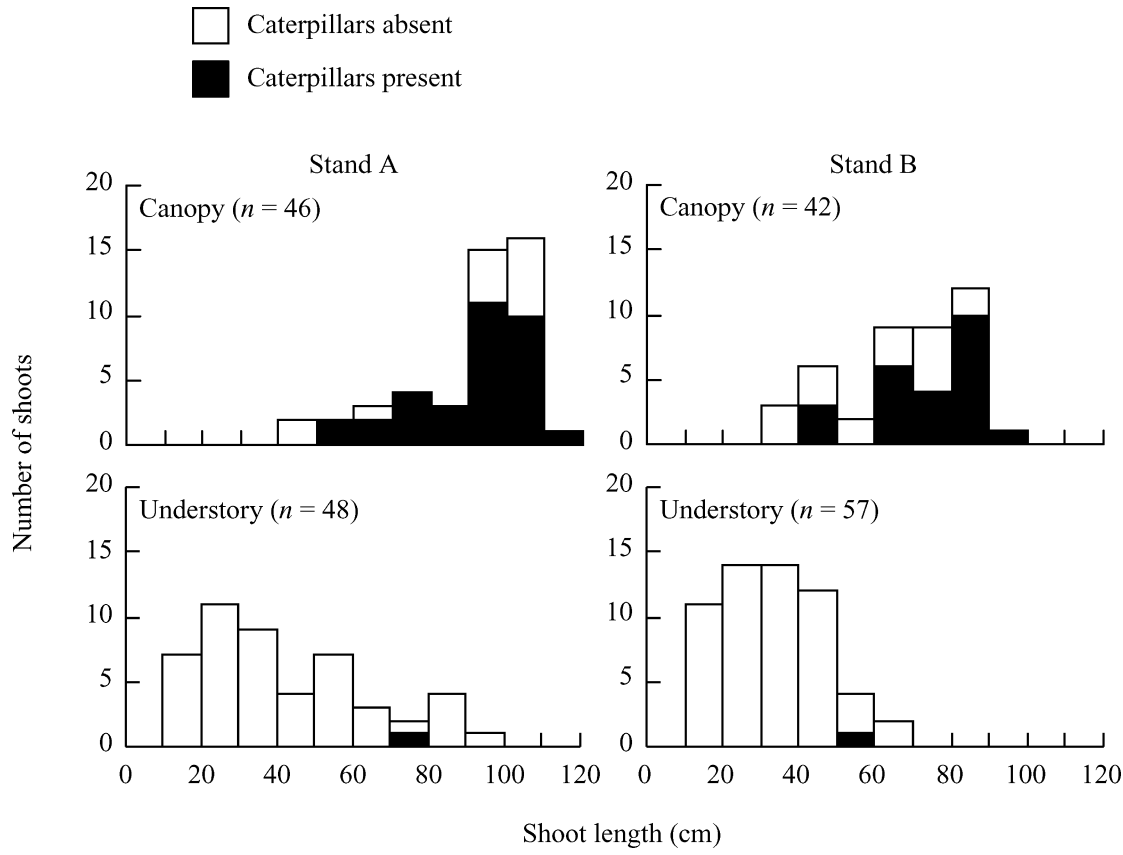

Fig. 1. Number of shoots on which Arcte coerulea caterpillars were present and absent.

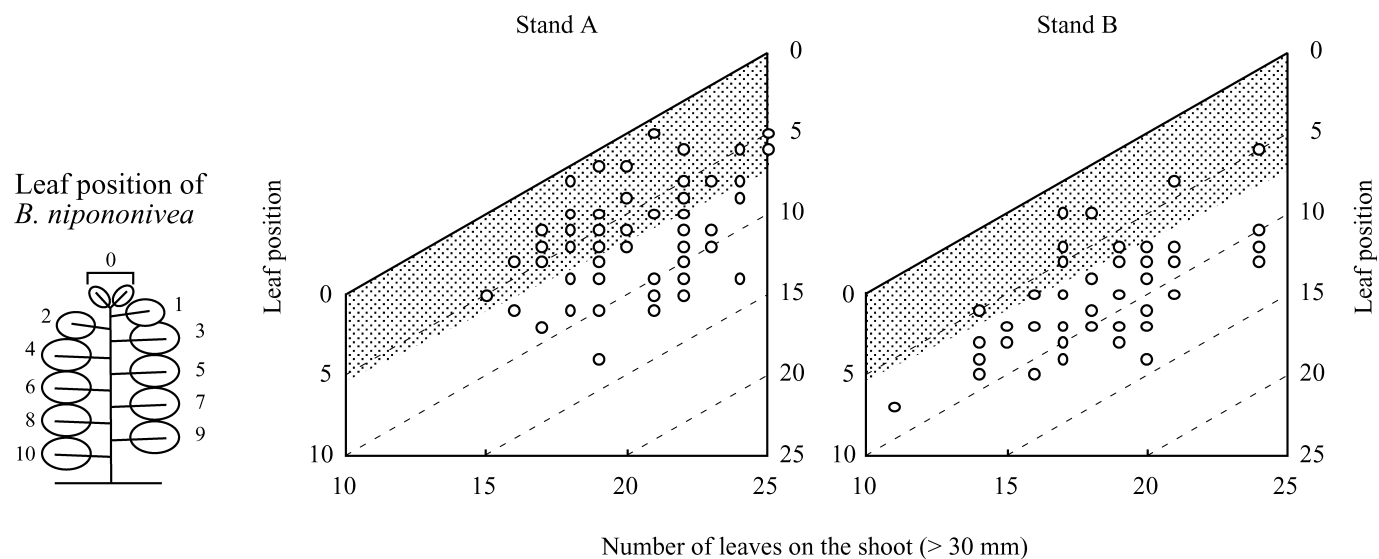

Fig. 2. Leaf positions on which Arcte coerulea caterpillars were found. Dashed lines indicate same leaf positions; shaded areas represent the range of expanding leaves.

\section{Insect performance}

All insects survived the experiment. Larval performance differed significantly among treatments (ANOVA, $F_{4,85}=29.53, p<0.0001$; Fig. 3). The best larval growth occurred on mature canopy leaves, i.e., those leaves were a superior resource for $A$. coerulea caterpillars. Leaf buds were the most inferior resource, irrespective of light availability, and resulted in poor larval performance.

\section{DISCUSSION}

Caterpillars of $A$. coerulea used canopy shoots in ramie stands, but were rarely observed on understory shoots. Canopy shoots produced new leaves more frequently, and grew longer than did understory shoots, i.e., the canopy shoots were more vigorous. Because sunlit plants often contain higher concentrations of chemical defenses than do shaded plants (Koricheva et al., 1998; Orians and Jones, 2001), canopy shoots of ramie are thought to be better protected than are understory shoots. 


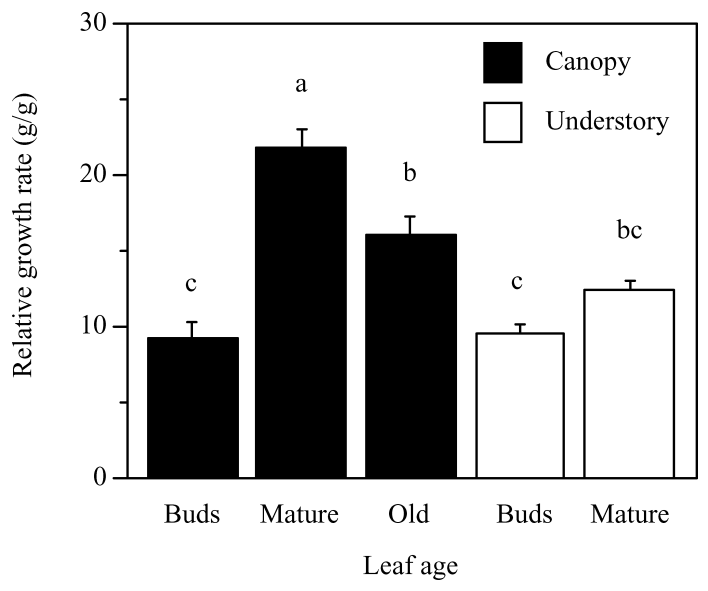

Fig. 3. Effect of leaf age on the relative growth rate of Arcte coerulea caterpillars. Means \pm SE are presented. Different letters indicate significant differences among treatments (ANOVA with post hoc Tukey HSD multiple comparisons, $p<0.05)$.

However, the performance of $A$. coerulea caterpillars was better when they fed on mature canopy leaves than on understory leaves. This was probably because caterpillars could obtain more nutrition from the sunlit shoots, suggesting that these caterpillars have the ability to overcome the host plant defenses. Among the canopy shoots, caterpillars showed a slight preference for longer shoots. This may indicate that longer and more vigorous shoots are better foods than shorter shoots, as in many other plant-herbivore systems (e.g., Price and Ohgushi, 1995; Woods et al., 1996; Fritz et al., 2000; Inbar et al., 2001).

Caterpillars were mainly found on leaves at the middle of shoots, and they never used the buds. The leaf positions on which caterpillars were found were lower as the shoot leaf number increased. Long ramie shoots with many leaves produced new leaves more frequently than did small shoots, and therefore a leaf on a long shoot was situated at a lower position than a leaf on a short shoot when both leaves were the same age (unpublished data). The distribution pattern of similar-aged leaves was probably reflected by the distribution patterns of caterpillars on shoots with different numbers of leaves, suggesting that the caterpillars preferred specific developmental stages of leaves. According to another investigation at a ramie stand near this study site (unpublished data), the leaf positions of leaves that had just completed expansion were consistent with the within-shoot caterpillar distribution
(Fig. 2). Because larval performance was best on mature leaves that had just completed expansion, the leaf preference of caterpillars is thought to be affected by changes in food quality with leaf age. In some insects, preferential feeding on leaves of a specific age is determined by leaf thickness, photosynthetic activity, or other factors that change with leaf age (Hartnett and Bazzaz, 1984; Nahrung et al., 2001; Wait et al., 2002).

In general, the concentrations of qualitative chemical defenses in leaves of herbaceous plants decreases with age (Bowers and Stamp, 1993; van Dam et al., 1994, 1996; Kessler and Baldwin, 2002; Lambdon et al., 2003). Such plant defenses are generally effective against generalist herbivores that use a wide range of plant hosts, whereas they have little effect on specialist herbivores that are well adapted to the host plants (van der Meijden, 1996; Wittstock and Gershenzon, 2002). Therefore, specialist herbivores may be found on plant buds, but generalists are frequently found on older leaves (Cates, 1980; van der Meijden, 1996; de Boer, 1999). Although A. coerulea is a specialist herbivore that has an ability to overcome the host plant's defenses, no caterpillars were found on buds. Moreover, when caterpillars were forced to feed on buds, their performance was poor. Because buds usually contain enough nutrients (Harper, 1989; Bowers and Stamp, 1993; Suzuki, 1998), the poor performance of caterpillars may have been caused by exceedingly strong bud defenses such as toxic secondary metabolites that even these specialists were not able to overcome. Buds of $B$. nipononivea have many hairs (Osada, 1981), and they may also act as defensive devices.

When most leaves are consumed during an outbreak of herbivores, plants usually regrow using resources stored in herbivore-free organs such as rhizomes (Stowe et al., 2000). Rapid regrowth of foliage after heavy herbivory can reduce the loss of plants. Therefore, the survival of meristems and other organs for regrowth after herbivory affects plant tolerance, i.e., the ability to grow under conditions of disease or severe herbivory (Stowe et al., 2000). Arcte coerulea caterpillars outbreak frequently in Japan (Ohtaishi, 1977). However, when outbreaks occur and caterpillars consume a majority of the ramie leaves, the buds are not eaten. After an outbreak, new leaves grow from buds that are left intact (J.-Y. Ide, personal observation). 
Ramie shrubs with strong bud defenses may have been favored to regrow rapidly after $A$. coerulea outbreaks. At the same time, A. coerulea caterpillars feed on the a little firmly defended mature leaves of vigorous shoots; they may not have evolved the ability to feed on buds because it would be costly to overcome the strong bud defenses. Further research is necessary to clarify the inter- and intra-shoot distribution of nutrients and defensive chemicals in ramie shrubs, and to compare them with the distribution of caterpillars.

\section{ACKNOWLEDGEMENTS}

I thank Dr N. Ohsaki for his critical reading of the manuscript, and I am grateful to members of the Laboratory of Insect Ecology and the Laboratory of Ecological Information, Graduate School of Agriculture, Kyoto University, for their discussions and comments.

\section{REFERENCES}

Aide, T. M. (1993) Patterns of leaf development and herbivory in a tropical understory community. Ecology 74 : 455-466.

Bowers, M. D. and N. E. Stamp (1993) Effects of plant age, genotype, and herbivory on Plantago performance and chemistry. Ecology 74: 1778-1791.

Cardoza, Y. J., H. J. McAuslane and S. E. Webb (2000) Effect of leaf age and silverleaf symptoms on oviposition site selection and development of Bemisia argentifolii (Homoptera: Aleyrodidae) on Zucchini. Environ. Entomol. 29: 220-225.

Cates, R. G. (1980) Feeding patterns of monophagous, oligophagous, and polyphagous insect herbivores: the effect of resource abundance and plant chemistry. Oecologia 46: 22-31.

Coley, P. D., J. P. Bryant and F. S. Chapin III (1985) Resource availability and plant antiherbivore defense. Science 230: 895-899.

de Boer, N. J. (1999) Pyrrolizidine alkaloid distribution in Senecio jacobaea rosettes minimises losses to generalist feeding. Entomol. Exp. Appl. 91: 169-173.

Esaki, T., S. Issiki, A. Mutuura, H. Inoue, H. Okagaki, M. Ogata and H. Kuroko (1971) Moths of Japan in Color. Vol. II (Revised edition). Hoikusha, Osaka. 304 pp. (in Japanese).

Fordyce, J. A. and A. A. Agrawal (2001) The role of plant trichomes and caterpillar group size on growth and defence of the pipevine swallowtail Battus philenor. $J$. Anim. Ecol. 70: 997-1005.

Fritz, R. S., B. A. Crabb and C. G. Hochwender (2000) Preference and performance of a gall-inducing sawfly: a test of the plant vigor hypothesis. Oikos 89: 555-563.

Harper, J. L. (1989) The value of a leaf. Oecologia 80: 5358.

Hartnett, D. C. and F. A. Bazzaz (1984) Leaf demography and plant-insect interactions. Am. Nat. 124: 137-142.
Ikemoto, H. (1984) The effect of ligation on the density-related larval color change of the ramie moth, Arcte coerulea Guenée (Lepidoptera: Noctuidae). Appl. Entomol. Zool. 24: 150-151.

Inbar, M., H. Doostdar and R. T. Mayer (2001) Suitability of stressed and vigorous plants to various insect herbivores. Oikos 94: 228-235.

Kessler, A. and I. T. Baldwin (2002) Manduca quinquemaculata's optimization of intra-plant oviposition to predation, food quality, and thermal constraints. Ecology 83: 2346-2354.

Koricheva, J., S. Larsson, E. Haukioja and M. Keinänen (1998) Regulation of woody plant secondary metabolism by resource availability: hypothesis testing by means of meta-analysis. Oikos 83: 212-226.

Lambdon, P. W., M. Hassall, R. R. Boar and R. Mithen (2003) Asynchrony in the nitrogen and glucosinolate leaf-age profiles of Brassica: is this a defensive strategy against generalist herbivores? Agric. Ecosyst. Environ. 97: 205214.

Nahrung, H. F., P. K. Dunstan and G. R. Allen (2001) Larval gregariousness and neonate establishment of the eucalypt-feeding beetle Chrysophtharta agricola (Coleoptera: Chrysomelidae: Paropsini). Oikos 94: 358-364.

Ohtaishi, M. (1977) Phase variation and warning behaviour in the larva of Arcte coerulea. Insectarium 14: 128-131 (in Japanese).

Orians, C. M. and C. G. Jones (2001) Plants as resource mosaics: a functional model for predicting patterns of within-plant resource heterogeneity to consumers based on vascular architecture and local environmental variability. Oikos 94: 493-504.

Osada, T. (1981) Colored Guide of Wild Herbs with Artificial Key to Their Families. Hoikusha, Osaka. 518 pp. (in Japanese).

Price, P. W. (1991) The plant vigor hypothesis and herbivore attack. Oikos 62: 244-251.

Price, P. W. and T. Ohgushi (1995) Preference and performance linkage in a Phyllocolpa sawfly on the willow, Salix miyabeana, on Hokkaido. Res. Popul. Ecol. 37: 23-28.

Stowe, K. A., R. J. Marquis, C. G. Hochwender and E. L. Simms (2000) The evolutionary ecology of tolerance to consumer damage. Annu. Rev. Ecol. Syst. 31: 565-595.

Suzuki, S. (1998) Leaf phenology, seasonal changes in leaf quality and herbivory pattern of Sanguisorba tenuifolia at different altitudes. Oecologia 117: 169-176.

Van Alstyne, K. L., J. J. McCarthy III, C. L. Hustead and L. J. Kearns (1999) Phlorotannin allocation among tissues of northeastern pacific kelps and rockweeds. J. Phycol. 35: 483-492.

van Dam, N. M., T. J. de Jong, Y. Iwasa and T. Kubo (1996) Optimal distribution of defences: are plants smart investors? Funct. Ecol. 10: 128-136.

van Dam, N. M., R. Verpoorte and E. van der Meijden (1994) Extreme differences in pyrrolizidine alkaloid levels between leaves of Cynoglossum officinale. Phytochemistry 37: 1013-1016

van der Meijden, E. (1996) Plant defence, an evolutionary dilemma: contrasting effects of (specialist and generalist) 
herbivores and natural enemies. Entomol. Exp. Appl. 80: 307-310.

Wait, D. A., J. S. Coleman and C. G. Jones (2002) Chrysomela scripta, Plagiodera versicolora (Coleoptera: Chrysomelidae), and Trichoplusia ni (Lepidoptera: Noctuidae) track specific leaf developmental stages. Environ. Entomol. 31: 836-843.

White, T. C. R. (1984) The abundance of invertebrate herbivores in relation to the availability of nitrogen in stressed food plants. Oecologia 63: 90-105.

Wittstock, U. and J. Gershenzon (2002) Constitutive plant toxins and their role in defense against herbivores and pathogens. Curr. Opin. Plant Biol. 5: 300-307.

Woods, J. O., T. G. Carr, P. W. Price, L. E. Stevens and N. S. Cobb (1996) Growth of coyote willow and the attack and survival of a mid-rib galling sawfly, Euura sp. Oecologia 108: 714-722. 